\title{
Recurrent squamous cell carcinoma of the skin treated successfully with single agent cetuximab therapy
}

This article was published in the following Dove Press journal:

OncoTargets and Therapy

25 February 2016

Number of times this article has been viewed

\author{
Selcuk Seber' \\ Aylin Gonultas ${ }^{2}$ \\ Ozlem Ozturk ${ }^{2}$ \\ Tarkan Yetisyigit \\ 'Department of Medical Oncology, \\ Faculty of Medicine, Namık Kemal \\ University, ${ }^{2}$ Pathology Department, \\ Tekirdag State Hospital, Tekirdag, \\ Turkey
}

Correspondence: Selcuk Seber Department of Medical Oncology, Faculty of Medicine, Namık Kemal University Hospital, Yuzuncu Yil Mah Tunca Street, Suleymanpasa, Tekirdag 59000, Turkey Tel +90532502882I

Email selcukseber@gmail.com

\begin{abstract}
Recurrent squamous cell carcinoma of the skin is a rare but difficult to treat condition. Frequently, the disease presents itself in elderly patients with poor performance status and bearing many comorbidities, thus the decision to administer systemic chemotherapy becomes difficult to make. In addition, current chemotherapeutic protocols response rates are far from satisfactory. Recently cetuximab, a chimeric antibody against epidermal growth factor receptor, is increasingly being reported as an alternative treatment. We therefore report this case of a recurrent squamous cell carcinoma of the skin in an elderly woman with poor performance status and who had an excellent clinical response to single agent cetuximab therapy with complete resolution of the disease and minimal toxicity during the course of the treatment to provide evidence for future prospective clinical trials.
\end{abstract}

Keywords: cetuximab, EGFR inhibiton, squamous cell carcinoma of the skin

\section{Introduction}

Squamous cell carcinoma of the skin (SCCS) is a common malignancy representing nearly $25 \%$ of the nonmelanoma skin cancer. Its incidence is expected to increase worldwide due to aging population and an increasing exposure to ultraviolet radiation. Initial treatment for SCCS is a wide surgical excision of the lesion. When the patients present with locally recurrent disease not amenable for surgery (due to location of the lesion or widespread disease) or with metastatic disease, there are a few options for treatment. ${ }^{1}$

Most of the studies assessing the efficacy of systemic treatments in advanced SCCS are nonrandomized and retrospective. Cisplatin-based chemotherapy forms the backbone of the treatment and high response rates have been reported in the literature. ${ }^{2,3}$ However, the majority of the patients who present to the clinic with advanced disease are elderly individuals who are in poor clinical condition and carry several comorbidities. Cisplatin-based chemotherapy is known for its commonly encountered adverse effects such as nausea and vomiting, low blood counts, and, especially, nephrotoxicity. Although these adverse effects are easily treatable in the more young and fit patient population, they are hard to manage in frail elderly patients with poor performance status. ${ }^{4}$

Cetuximab is a human and mouse chimeric antibody against epidermal growth factor receptor (EGFR). It is currently used in upper aerodigestive tract squamous cell cancers in conjunction with cisplatin and/or radiotherapy. ${ }^{5}$ Cetuximab has a low toxicity profile with good patient tolerance. Most commonly cited adverse effects can be listed as drug hypersensitivity reactions, acneiform rash, and diarrhea. 
These side effects are either frequently low grade or otherwise can easily be managed without affecting the patient's quality of life. ${ }^{6}$

We describe the case of an elderly patient in fragile condition due to the advanced SCCS. Her deteriorating nutritional status due to tumor mass in the neck region, which prevented oral food intake, further added to the poor clinical status of the patient. Written informed consent was obtained from the patient for the publication of this case report and any accompanying images. Approval from an ethics committee was not required due to being a retrospective study and the information regarding the case is anonymous.

\section{Case report}

An 83-year-old female patient presented to outpatient oncology clinic with a large ulcerated nodule located in the left cheek and extending into the left neck region. Five years ago, a previously documented squamous cell skin cancer lesion located in the left mandibular region was excised with clear margins. The lesion recurred 12 months before presentation to the medical oncology clinic; however, due to poor socioeconomic status she was unable to admit to the hospital. Her clinical condition recently deteriorated because the cancerous lesion became too painful and she was not capable of oral food intake any longer. Radiation oncology department decided that it would be difficult for the patient to tolerate radiotherapy because the lesion was deeply ulcerated and it was occupying a large region of the left side of the face. A tissue biopsy was taken to confirm tumor recurrence (Figure 1). A computer tomography of the head and neck region demonstrated extensive soft tissue invasion of the tumor. She was referred to medical oncology department for chemotherapy. Standard cisplatin-based chemotherapy was not

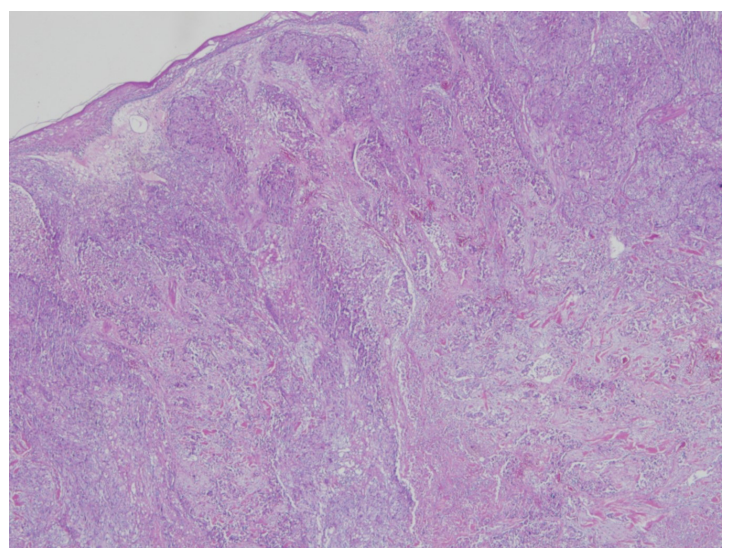

Figure I Biopsy of the patient's tumor (H\&E 20×10): tumor islands comprised of poorly differentiated squamous cancer cells having intercellular bridges with macronucleoli and hyperchromatic vesicular nuclei.

Abbreviation: H\&E, hematoxylin and eosin. found appropriate because of the patient's poor clinical status and therefore a decision was made to start her treatment with single agent cetuximab.

The patient was treated with cetuximab administered at a dose of $400 \mathrm{mg} / \mathrm{m}^{2}$ every 15 days, from September 29, 2013 to April 10, 2014. After the second cycle of the treatment, performance status improved and regression of the ulcerous lesion was visually observed. While the treatment continued, grade 2 acneiform rash on her face, neck, and mediastinum developed, which was successfully treated with vitamin K1 cream without needing dose reduction. She developed grade 3 anemia at the fifth month of treatment, which was treated with red blood cell transfusions as needed and the treatment was stopped at the end of 6 months because she denied any further therapy. The tumor lesion had completely regressed at the time the treatment was terminated (Figure 2). At her last follow-up visit, which was 12 months after the end of cetuximab therapy, she was still in complete clinical remission.

\section{Discussion}

EGFR expression is common in SCCS. ${ }^{7}$ Cetuximab is a monoclonal antibody that is directed against the extracellular domain of EGFR. After binding of cetuximab to EGFR, the ligand receptor complex is internalized and EGFR expression is downregulated in the cell surface. As a result, EGFR-dependent activation of tyrosine kinases associated with cell growth, proliferation, angiogenesis, and motility is inhibited. EGFR expression and a low incidence of KRAS mutations in skin cancers provide a rationale for investigation of cetuximab in the treatment of advanced SCCS. ${ }^{8}$

In a recent Phase II study, the efficacy of cetuximab was assessed in patients with unresectable SCCS. ${ }^{9}$ In this prospective study, which included only 36 patients, disease control rate was reported as $67 \%$ and the median duration of response in patients achieving a complete or partial response was 6.8 months. In the study population, the relation between status of several genetic mutations and gene polymorphisms with patient outcome was also investigated. There were two complete responses that had been followed up to 2 years without recurrence. Our case also had a complete response that had been followed for more than 12 months without disease recurrence. BRAF/KRAS/NRAS mutation was not detected in any member of the study population.

Apart from this randomized study, there are several case reports or case series reported in the literature describing partial or complete remission with cetuximab therapy in the setting of advanced SCCS. ${ }^{10}$ Although the overall response 

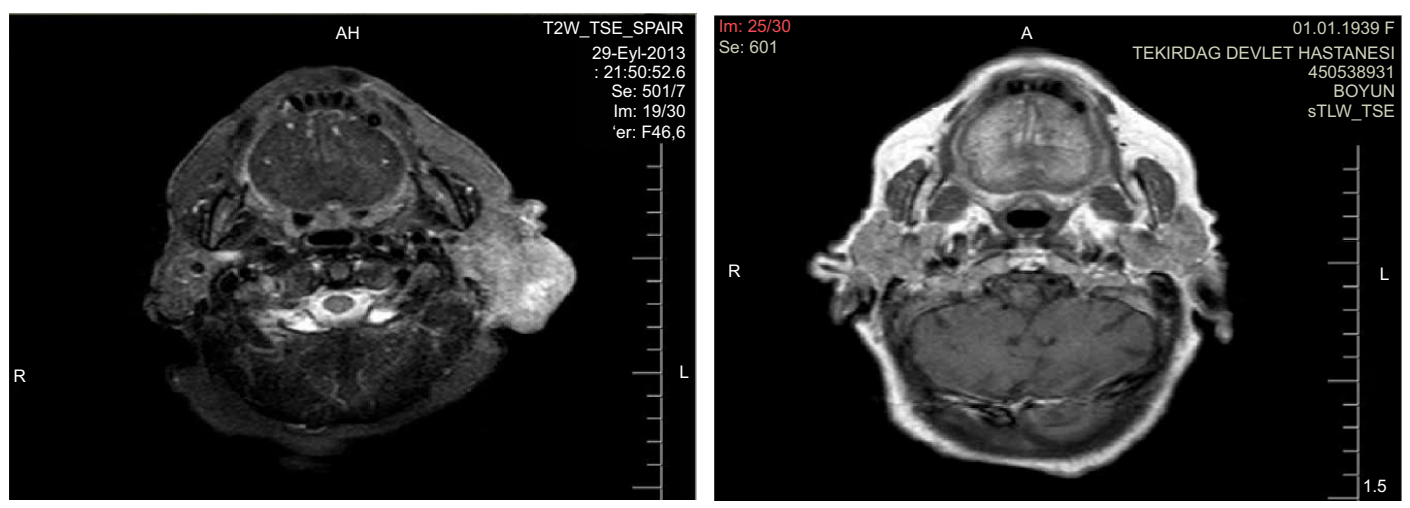

Figure 2 Computer tomography scan showing response of the tumorous lesion to the cetuximab treatment located at the postauricular region extending to the parotid capsule.

rate is reported to be higher in cases where cetuximab is given in conjunction with concomitant radiotherapy, there are several cases where complete responses have been achieved with single agent cetuximab. Maximum disease control rate is reported to be achieved at weeks 6-8 of treatment in several studies. ${ }^{9,11}$ Average lack of $N R A S / K R A S$ mutations in SCCS may be responsible for the favorable response rate to cetuximab. ${ }^{10,12}$

There are two older Phase II studies involving patients with advanced SCCS that evaluated the efficacy of targeted therapies. Combination of 13-cis-retinoic acid and interferon alpha was reported to have a high response rate; however, adverse event rates and toxicity profiles (febrile neutropenia, thrombocytopenia, anemia, nausea/vomiting) were higher in both studies compared to cetuximab monotherapy. ${ }^{13,14}$ Cetuximab treatment with its relatively low toxicity profile could be considered a more suitable treatment alternative in the elderly population of patients with low performance status.

The safety profile and tolerability of cetuximab in SCCS patients is very good as reported previously. As was the case in our patient, grade 1 to 2 acneiform rash was reported to be associated with increased response rate and prolonged survival. ${ }^{9,15-17}$

A predictive marker of clinical response to cetuximab chemotherapy in skin squamous cell cancer has not been previously defined. Whether EGFR immunostaining predicts response to anti-EGFR therapy is a controversial issue. While EGFR immunostaining does not predict response to cetuximab treatment in colon cancer, high levels of EGFR expression is reported to be correlated with treatment response to EGFR blockade in metastatic squamous cell lung carcinoma. Clinical studies suggest that expression rather than EGFR mutation is predictive for response to cetuximab in metastatic cutaneous squamous cell carcinomas. ${ }^{18}$ Unfortunately, the
Phase II study only included patients with positive EGFR expression in the study group excluding the one patient whose tumor did not express the tyrosine kinase receptor. ${ }^{9}$ Interestingly we did not detect EGFR expression by immunohistochemistry (IHC) method in our case.

\section{Conclusion}

Our case demonstrates that cetuximab monotherapy is a plausible treatment alternative for patients with advanced SCCS; especially for those elderly patients who are not suitable for combination chemotherapy or radiotherapy. We think that there is enough encouraging data in literature to carry out further Phase III research studies to clearly identify the role of this promising treatment modality in advanced SCCS patients.

\section{Disclosure}

The authors report no conflicts of interest in this work.

\section{References}

1. Palyca P, Koshenkov VP, Mehnert JM. Developments in the treatment of locally advanced and metastatic squamous cell carcinoma of the skin: a rising unmet need. Am Soc Clin Oncol Educ Book. 2014: e397-e404.

2. Guthrie TH Jr, Porubsky ES, Luxenberg MN, Shah KJ, Wurtz KL, Watson PR. Cisplatin-based chemotherapy in advanced basal and squamous cell carcinomas of the skin: results in 28 patients including 13 patients receiving multimodality therapy. J Clin Oncol. 1990; 8(2):342-346.

3. Cranmer LD, Engelhardt C, Morgan SS. Treatment of unresectable and metastatic cutaneous squamous cell carcinoma. Oncologist. 2010; 15(12):1320-1328.

4. Alexa T, Lavinia A, Luca A, Miron L, Alexa ID. Incidence of chemotherapy discontinuation and characteristics of elderly patients with nonsmall cell lung cancer treated with platinum-based doublets. Contemp Oncol (Pozn). 2014;18(5):340-343

5. Petrelli F, Coinu A, Riboldi V, et al. Concomitant platinum-based chemotherapy or cetuximab with radiotherapy for locally advanced head and neck cancer: a systematic review and meta-analysis of published studies. Oral Oncol. 2014;50(11):1041-1048. 
6. van der Linden N, van Gils CWM, Pescott CP, Buter J, Vergeer MR, Groot CA. Real-world cost-effectiveness of cetuximab in locally advanced squamous cell carcinoma of the head and neck. Eur Arch Otorhinolaryngol. 2015;272:2007-2016.

7. Krähn G, Leiter U, Kaskel P, et al. Coexpression patterns of EGFR, HER2, HER3 and HER4 in non-melanoma skin cancer. Eur J Cancer. 2001;37(2):251-259.

8. Maubec E, Duvillard P, Velasco V, Crickx B, Avril MF. Immunohistochemical analysis of EGFR and HER-2 in patients with metastatic squamous cell carcinoma of the skin. Anticancer Res. 2005;25: 1205-1210.

9. Maubec E, Petrow P, Scheer-Senyarich I, et al. Phase II study of cetuximab as first-line single-drug therapy in patients with unresectable squamous cell carcinoma of the skin. J Clin Oncol. 2011;29(25): 3419-3426.

10. Wollina U. Update of cetuximab for non-melanoma skin cancer. Expert Opin Biol Ther. 2014;14(2):271-276.

11. Conen KL, Fischer N, Hofbauer GF, et al. Cetuximab in metastatic squamous cell cancer of the skin: a Swiss case series. Dermatology. 2014;229(2):97-101.
12. Wollina U. Cetuximab in non-melanoma skin cancer. Expert Opin Biol Ther. 2012;12(7):949-956.

13. Shin DM, Glisson BS, Khuri FR, et al. Phase II and biologic study of interferon alfa, retinoic acid, and cisplatin in advanced squamous skin cancer. J Clin Oncol. 2002;20(2):364-370.

14. Lippman SM, Parkinson DR, Itri LM, et al. 13-cis-retinoic acid and interferon alpha-2a: effective combination therapy for advanced squamous cell carcinoma of the skin. J Natl Cancer Inst. 1992;84(4):235-241.

15. Eder J, Simonitsch-Klupp I, Trautinger F. Treatment of unresectable squamous cell carcinoma of the skin with epidermal growth factor receptor antibodies - a case series. Eur J Dermatol. 2013;23(5):658-662.

16. Bauman JE, Eaton KD, Martins RG. Treatment of recurrent squamous cell carcinoma of the skin with cetuximab. Arch Dermatol. 2007; 143(7):889-892.

17. Alter M, Satzger I, Mattern A, Kapp A, Gutzmer R. Treatment of advanced cutaneous squamous cell carcinomas with epidermal growth factor receptor inhibitors. Dermatology. 2013;227(4):289-294.

18. Lee SM. Is EGFR expression important in non-small cell lung cancer? Thorax. 2006;61(2):98-99.
OncoTargets and Therapy

\section{Publish your work in this journal}

OncoTargets and Therapy is an international, peer-reviewed, open access journal focusing on the pathological basis of all cancers, potential targets for therapy and treatment protocols employed to improve the management of cancer patients. The journal also focuses on the impact of management programs and new therapeutic agents and protocols on

\section{Dovepress}

patient perspectives such as quality of life, adherence and satisfaction The manuscript management system is completely online and includes a very quick and fair peer-review system, which is all easy to use. Visit http://www.dovepress.com/testimonials.php to read real quotes from published authors. 